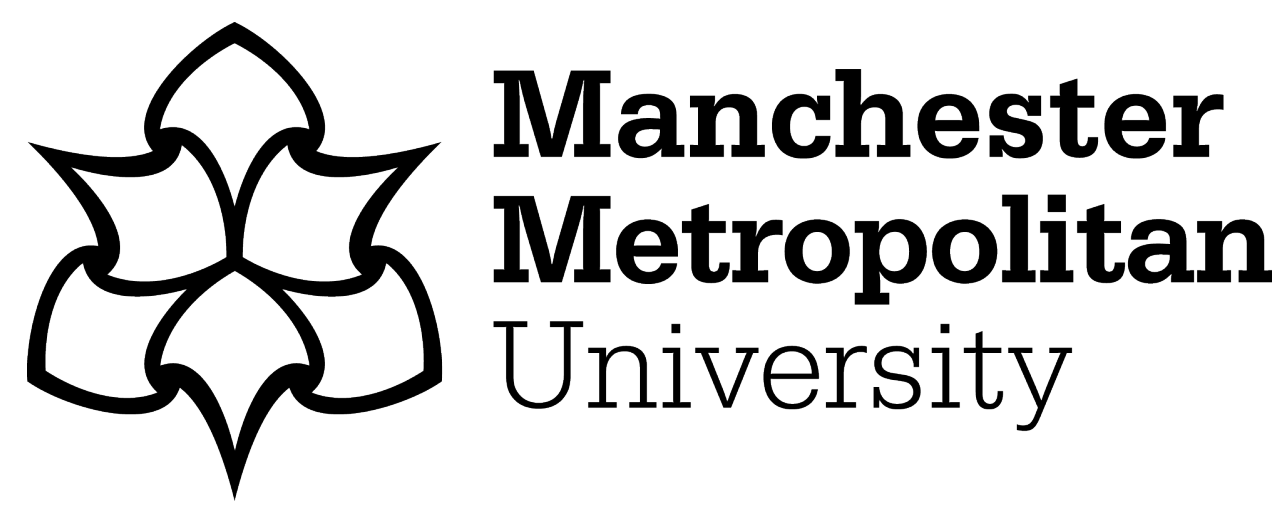

Barron, lan and Taylor, L (2017) Eating and scraping away at practice with two year olds. Pedagogy, Culture and Society, 25. pp. 567-581. ISSN 14681366

Downloaded from: https://e-space.mmu.ac.uk/618180/

Version: Accepted Version

Publisher: Taylor \& Francis

DOI: https://doi.org/10.1080/14681366.2017.1305437

Please cite the published version 


\title{
Eating and scraping away at practice with two-year-olds
}

Ian Barron, Educational and Social Research Institute, Faculty of Education, Manchester Metropolitan University, 53 Bonsall Street, Hulme, Manchester, M15 6GX. i.barron@mmu.ac.uk,(00)441612076

Lisa Taylor, Martenscroft Nursery School and Children's Centre, 33 Epping Street, Manchester, M15 6PA.

1.taylor@martenscroft.manchester.sch.uk, (00) 441612261266

\begin{abstract}
This paper examines how early childhood policy initiatives in the United Kingdom and internationally currently reflect neoliberal concerns with school readiness in the development of human capital and what diverse theoretical perspectives might offer. The focus is a project involving a group of early childhood academics from one university and a small group of practitioners from a range of early years' settings in the North of England. In thinking about practice, the paper explores a number of 'lines of flight', drawing on literature, philosophy and sociology to eat and scrape away at how provision for young children is commonly understood. What emerges from the scraping is not the clarity of fixities but the need for the weaving of resemblances that constantly transform meanings. We offer an engagement with heterogeneous theoretical ideas to help us think differently about the negotiation of ethical and equitable practices with children.
\end{abstract}

\section{Key words}

Neoliberalism, heterotopia, parallax, haunting, ethics, equity

\section{Corresponding author:}

Ian Barron, Faculty of Education, Manchester Metropolitan University, 53 Bonsall Street, Manchester, M15 6GX, UK.

Email: i.barron@mmu.ac.uk 


\section{The Project and its Policy Context}

This paper examines how current early childhood policy initiatives in the United Kingdom and internationally reflect dominant neoliberal concerns with school readiness in the development of human (economic) capital. The focus is a professional development project's first phase of that began in 2013 and ran over seven sessions for 30 months. Participants were a group of early childhood academics from one university and a small group of practitioners from four early years' settings in Northern England. The authors are Ian, an academic, who took part in a small number of the professional development sessions (of which more later) but had a much larger role in writing project papers; and Lisa, the deputy head teacher from one of the early years' settings, who attended almost all of the development sessions, kept a research journal and has contributed to the writing of this paper.

The paper's approach is rhizomatic (Deleuze and Guattari 2004), following 'lines of flight' to reflect upon and theorise the project. Drawing upon Kafka's novel The Castle (1999), Lacan's notion of the mirror stage (2001), Foucauldian notions of power (2002a) and heterotopia (1984, 2000a, 2000b, 2002a, 2002b, 2010) and Gordon's (2011) concept of haunting, we discuss two of the professional development sessions, and the emerging ideas and reflections. The other development sessions are discussed elsewhere by the same main authors (Barron et al 2017) in a paper which considers notions of professional development and the project's methodology; these matters receive less attention here. The final part of the paper discusses the challenges and experiences of learning and of emotional and equitable ethical work with two-year-olds.

The project was troubled by the hegemonic discourses underpinning traditional psychological accounts of child development where the emphasis is on growth, development from within and certain forms of literacy, numeracy and behavioural conformity. It reflected Blaise et al's attention (2016) to 'matters of concern' rather than 'matters of fact'. We explored claims that 'teaching ... should be focused on improving children's "school readiness" in order to "take full advantage of the learning opportunities available to them' (Department for Education [DfE] 2011, 62) and the Early Years Foundation Stage's commitment (EYFS, DfE 2014, 5) to provide 'the best possible start in life' by setting out expectations for children's learning, development and care from birth to the age of five that must be followed by all schools and Ofsted-registered early 
years settings . These government concerns have been influenced by neuroscience's claims (Shonkoff and Phillips 2000, Gopnik et al 2001) that 'impoverished' early experiences cause inadequate synapse development, with lifelong consequences. The policy backdrop regarding provision for and work with young children is thus marked by 'lines of articulation, or segmentarity, strata and territories' (Deleuze and Guattari 2004, $4)$ and by what Burman $(2016,19)$ has referred to as 'neurononsense'. Nonsense or not, the notion of some families providing impoverished experiences has a tendency to pathologise them as deviant and inadequate. We were much more concerned with how to work differently and more democratically (Bath and Karlsson 2016) with children so that 'gestural, memetic, ludic and other semiotic systems regain their freedom and extricate themselves from the “tracing”.' (Deleuze and Guattari 2004, 16).

\section{The Project and The Castle}

The university hosted the professional development sessions, except for one held at a local museum, and half a dozen academics worked with the practitioners. A few practitioners and academics attended all of the development sessions, most attended regularly, some only occasionally. The practitioners' settings included primary and nursery schools, a combined nursery school and children's centre and one run by the voluntary sector; most were teachers but some were teaching assistants. There was one newly established class for two-year-olds in a primary school with no prior experience with such young children. There were two local authority nursery schools, one also running a small group of children's centres. As noted previously, Barron et al (2017) consider the research methodology and space permits only a few comments here. Narrative accounts of the professional development sessions were kept by practitioners and some were then developed at greater length and with more distance as part of the emerging research. All except the first session were video recorded. Four months after the project, the recordings were edited by Leanne, a research assistant, bringing key moments together as a fourminute distillation of each session. Two months after this, some of the academics interviewed the practitioners about how the project had subsequently influenced practice. The use of video recording, written narratives and reliance on memory necessarily mean that what stays with us (as 'research evidence') is partial, capturing only certain aspects. Our primary concern was to develop an approach promoting 'experimentation in contact with the real' (Deleuze and Guattari 2004, 13) but the research evidence from the 
professional development sessions and the development sessions themselves can never be synonymous.

Following a first line of flight, the operation of power in Kafka's The Castle (1999) offers some potential in seeking to understand the project's quest. We are slowed down as we seek to understand K's experiences, seemingly adrift in a nameless village, called to 'the Castle' for no clearly stated reason in a quest to understand why his job offer as a land surveyor has apparently been withdrawn. Reading Kafka's novel, like taking part in the project, was an uncomfortable business. As someone with a senior management post, the project's ideas sat uncomfortably alongside my (Ian's) daily encounters with the neoliberal university's power and influence over my work. Power for Foucault (2002a, 340)

'operates on the field of possibilities in which the behaviour of active subjects is able to inscribe itself. It is a set of actions on possible actions; it incites, it induces, it seduces, it makes easier or more difficult; it releases or contrives, makes more probable or less; in the extreme, it constrains or forbids absolutely...'.

K. pays little attention to the needs and feelings of those he encounters, thereby creating difficulty and disadvantage for them. At the end of the unfinished novel, he has not reached the Castle. On occasion, my own concerns, actions and behaviours do not seem dissimilar to K.'s. The project involved working closely with others in ways that do not come easily to me. The active, physical and sensory approach also made me feel uncomfortable. Midproject, increased managerial commitments led me to withdraw from the professional development sessions but perhaps I did this too readily, acquiescing to university demands and abandoning project colleagues in the face of my own insecurities. A part of me yearned to be a land surveyor, a maker of maps, fostering 'connections between fields, the removal of blockages' (Deleuze and Guattari 2004, 13). However, in discomfort, perhaps, I returned to my position as caretaker for neoliberalism. Compliance with policy initiatives brings advantages (seduces in Foucault's 2002a terms) but requires caretaking of ideas and practice rather than innovation and the weaving of other possibilities.

We were concerned that the articulation and stratification of policy initiatives and the power exerted can, like the Castle, all too readily make us subject to 'a symbol of lifelessness and blind power (that) towers above everyone and everything' 
(Azizmohammadi 2012, 2245). This led to a determination that the professional development sessions should offer opportunities to resist. The first focused on the academics and practitioners getting to know each other and with discussions about the EYFS. The EYFS' messages, discourses, imperatives and practices recall the certainties of the Castle, many of which prove to be unreliable. Mindful of this, we were determined to shape a project that 'stops us from thinking that things speak for themselves' (MacLure 2010, 278). We were concerned that the approach should be interactional, dynamic and synaptic rather than 'the traditional top-down approach - where the teacher is ... at the bottom of the 'knowledge funnel', being handed someone else's ... 'best practices' to implement' (Martinovic et al 2012,400). Thus we used an approach that 'taps the knowledge of ..... mature individuals and practising professionals with insights to share ...' (Lapadat 2009, 975).

\section{Dissipating the Inner Shadow where the Enemy's Plots Are Woven}

Our particular interest was in challenging the sufficiency and bleakness of dominant policy discourses about appropriate early childhood experiences. Critical perspectives are increasingly used to disturb Enlightenment thinking in early childhood (Jones 2001, Ryan and Grieshaber 2005, Rhedding-Jones 2008, Burman 2016, Blaise et al 2016). Deleuze and Guattari (2004) use the metaphor of the tree and the rhizome to disrupt such thinking. The tree's trunk and branches, the discourses and dominant ideas of particular cultures and societies, are underpinned by the institutions and practices that provide their means of sustenance, circulation and anchoring. The concerns are thus with linear growth, development, logic, unity, beginnings and endings, finiteness. Instead of the tree, Deleuze and Guattari (2004) turn to the rhizome, where shoots go in all directions, may break off and start up again elsewhere, with ideas not necessarily being connected to any singular core. One of the project's concerns, however, was that despite such thinking in the academy, relatively little of this has found its way into early childhood practice.

In the face of the normalising discourses of the DfE (2015), the varied activities and engagement with a diverse range of theoretical ideas provided provocations, in the manner of the rhizome, to make 'connections between semiotic chains, organizations of power, and circumstances' (Deleuze and Guattari 2004,8). Thus the professional development sessions involved 'lines of flight, movements or deterritorisation and 
destratification' where 'rates of flow on these lines produce phenomena of relative slowness and viscosity, or on the contrary of acceleration and rupture' (Deleuze and Guattari 2004,23). These matters triggered in the project, and in the theory drawn upon in this paper, a rhizomatic approach where 'any point' can be connected to 'any other .... and its traits are not necessarily linked to traits of the same nature' (Deleuze and Guattari 2004,23).

Our imaginings in the paper have roamed nomadically across literature, philosophy and sociology whose ideas, during and subsequent to the project, have afforded lines of flight in considering early childhood practice. This has foregrounded useful concepts such as the Castle, power, heterotopia, the mirror, hauntings and the affective. This paper, like the project, connects these ideas as a rhizomatic assemblage. Instead of readily accepted understandings about the nature of early childhood institutions and practices (or those of the Castle in Kafka's novel), the project sought instead to loosen the 'apparatus of knowledge transmission' (Foucault 2002a, 78), disrupted the binary and worked with the conjunction 'and ... and .... and' (Deleuze and Guattari 2004, 27). The aim was to open up a 'space that eats and scrapes away' (Foucault, 2000, 178) at any sense of easy understanding, that seeks to make 'the whole proliferate' (Deleuze and Guattari 2004, 9).

It sought also to disrupt the hauntings that permeate the rhizomatic relationships between happenings, chronology, ideas, representation and interpretation. This led to an interest 'in movements, moving places and places that are continuously being transformed, and thus never can be pinpointed as such, except by pointing at resistant and queer forms of activism that endlessly subvert and redefine space' (Steyaert 2010, 63). We saw this as important ethical work that, in Foucault's words (2000a, 275), was concerned to 'dissipate the inner shadow where the enemy's plots are woven'. Hence development activities were at once both familiar and utterly uncomfortable. We clawed at both medieval belief in the natural order of society (which haunts The Castle alongside seemingly nineteenth and twentieth century practices) and Enlightenment belief that truths can be revealed and capabilities enhanced by scraping away at falsehood and adopting 'best practice'. This required engagement with Foucault's 'care of the self' which 'happens by radically questioning and upsetting the historically dominant practices and discourses ....' (Steyaert 2010, 48). 
The professional development sessions involved touch, sound, light, dark and physical exploration and sought not the clarity of fixities but the need for the constant weaving of resemblances that transform meanings. This involved 'resistance towards overcoded spaces' and keeping these 'open for ever new practices of self-formation' (Steyaert 2010, 48) as part of this process of caring for the self. We drew upon recent work referred to by writers such as Rautio (2014) and Hackett (2016), which explores the 'relationship between materiality, place and childhood' (Hackett, 2016: 170) and that referred to by Hohti $(2016,182)$ that 'unsettle(s) the taken-for-granted educational notions related to time and space'. This brings to mind how time and space are difficult to navigate in The Castle. Given that K.'s acceptance of norms leads him to succumb to the Castle's operation of power, this requires constant critique of what we 'already think we know as a truth about children's development and learning' and engagement with 'an ethics of potentialities, where it becomes impossible to judge, value or diagnose children in relation to pre-set ideas or truths' (Lenz Taguchi 2011, 47).

\section{Thinking and Talking About Two-Year Olds in Glass ('Jam') Jars}

$\mathrm{X}$ but not $\mathrm{W}$ was present at the subsequent professional development session, the first of the two being discussed in this paper. We were asked to encapsulate in a glass ('jam') jar what the two-year-old meant for us. The rationale for using this method in support of the project's aims is discussed in Barron et al (2017) and so is not repeated here but, in brief, the intention was for us to think about what characteristics or resemblances two-year-olds have in common and how we relate to them. Such jars are usually small and so this essence must be of a suitable size if it is to fit inside, leaving or shutting out anything that cannot be contained. The space of the jar thus has meaning in relation to the surrounding space, all that is not inside it. Hence, whatever is put in the jar represents what it is to be two years old, rather as some see mirrors and paintings as ways of reflecting and representing reality. Glass can allow us to see what is on the other side and there are meanings connected to scientific investigation, the keeping of specimens, but it can also distort what we see, which is thus both itself and something other.

Some participants chose practical things they considered children like, such as sand play. This led to discussion about whether this appeals to all children, about the 
possible reasons and about how we respond when children do not enjoy particular play materials. Discussions turned particularly on the processes by which some meanings about children come to be seen as more compelling, more 'natural', and so come to be privileged (and included in the jar), thereby excluding others. As importantly, it also involved consideration of whether we had thought sufficiently about the "things and doings that matter to children' (Hohti 2016, 189) and of whether other descriptions and explanations might be equally or more valuable. I (X) pondered whether to fill the jar with things illustrative of a two-year-old's interests and representative her experiences in her setting. I chose two play figures (one large, one small), a piece of elastic, a picture of a heart, a piece of fur infused with lavender oil, a stone and a picture of food. What led to these choices? The food denoted the importance of basic needs being met in order to thrive and learn. The stone represented being outdoors and the physicality of two-yearolds exploring spaces using their whole bodies. The fur embodied the senses and their importance in two-year-olds' explorations. The figures epitomised two-year-olds' relationships, how they are surrounded by bigger people and can feel small. It also evoked the confusion of a two-year-old making sense of their growing world. Sometimes they are small and in need of protection, learning new things, but at others they are the most dominant person. The elastic also reflected an ever-expanding world where the two-yearold stretches away from the adult then is pulled back. The heart symbolised how twoyear-olds' emotions are close to the surface and surface in different ways. For me (X), this emotional thread has carried on, eliciting feelings of pulled emotions in work with this age group and current reflections on the need for emotional connection when working with other practitioners and how that can effect change.

In The Castle, K. seems not to consider the emotions and needs of others and this appears to lie behind his quest's fruitlessness. Thus we felt that emotion was worthy of careful consideration. Whilst the significance of emotion is a growing feature of the literature, there is little that quite gets to the heart of what X discusses here. Elfer (2015) seems closest in saying that 'the task of being thoughtfully responsive to each child is an intellectually and emotionally demanding one'. (Elfer 2015, 506). Hochschild's (1983) seminal work is some of the earliest to refer to the emotional cost of practitioners' intense relationships with young children. Ecclestone \& Brunila (2015) and Burman (2016) highlight the way in which emotion is commodified and measured in neoliberalism, becoming part of the mechanisms of state control. Others pick up such themes in 
discussing the tensions in being part of a largely female workforce, expected to meet the attachment needs of young children, whilst at the same time often feeling a need to maintain some distance as self-protection from the intensity (see, for example: Elfer 2012, 2015). Connected to this are discussions of emotional resilience, with Osgood $(2010,130)$ saying that emotional work 'can be costly to practitioners and can deplete the psychic reserves' and Andrew $(2015,662)$ cautioning that 'there are times when their holdings of emotional capital may not be sufficient to deal with the stress'.

\section{The Complexities of Self, Other and the Mirror}

In seeking to explore theoretically these more social and emotional aspects of our assemblage of ideas about two-year-olds, our next line of flight takes us to Lacan's (2001) 'mirror stage'. Awareness of self in the mirror is played out beside the sense of the projected self but also against other people who reflect back elements of who the child is and is becoming. For Lacan, what is important is the child's struggle in the past, present and future to understand her/himself in relation to others and to an imagined and projected other: 'what is realised in my history is not the past definite of what was, since it is no more, or even the present perfect of what has been in what I am, but the future anterior of what I shall have been for what I am in the process of becoming' (Lacan 2001, 94). This conjured for us the emotional charge of working with two-year-olds, which perhaps stems from the emotional turbulence two-year-olds seem to experience. These notions were helpful in thinking about alternatives to seeing young children as limited and deficient through inexperience and relative dependency and move us towards experimentation, immanence and potentiality. The professional development sessions took us on a line of flight where we perhaps accessed some of the discomfort felt daily by two-year-olds as they engage with objects and activities which have only the beginnings of familiarity. We saw this as important as, in The Castle, failure to engage leads to K. being overwhelmed rather than transformed and transforming.

\section{Hauntings, Tracings, Paintings, Castles and Heterotopias}

Examining the ways in which dominant discourses circulate in early childhood involved constant searching for the ghosts haunting policy. Bourke and Lidstone $(2015,836)$ emphasize that 'some discourses dominate, not necessarily because they are more right or 
truthful, but because they ... exercise more strategic relations of power and have political strength'. This is what appears to happen in The Castle and seems also to be operating in discourses about school readiness. We sought to surface and disturb these processes. Gordon's work $(2011,3)$ on haunting seeks to make visible 'what's living and breathing in the place hidden from view'. Haunting elicits a 'contest over the future, over what's to come' (Gordon 2001, 31) and the possibility of doing things differently. The outcomes of the haunting are 'not wholly given and certainly not given permission by the system's logics or crises' (Gordon 2011, 8). What is needed is to engage with how 'the trace or remnant introduces a moment of fracture .... insights emerge that may or may not be sayable, when actions emerge that may or may not be actionable' (Yaeger 2005, 97). K.'s failed quest stems from conformity to the Castle's power, failing to do things differently, whilst ignoring others in the process. For us, conforming to dominant notions of school readiness would be to fail to create a space to think, feel, and act differently relative to how we work with two-year-olds.

Seeking to understand these discourses and how they linger as ghosts, we are reminded again of Kafka's novel (1999). In The Castle, things and people are never quite what they seem and so we follow a new line of flight to Foucault's notion of heterotopia (2002a, 2002b) where this is also the case. Our concern was with 'rediscovering the connections, encounters, supports, blockages, plays of force, strategies ... that at a given moment establish what subsequently counts as being self-evident, universal and necessary' (Foucault 2002a, 226-227) in relation to understandings about two-year-olds and the language commonly used to describe them. Wesselman (2013) helps operationalise the concept by identifying some key characteristics of heterotopias. Unlike idealised utopias, they exist as 'real spaces' but are not bounded by that physical form and are also imaginary and have meaning, through discourse. Hetherington $(2011,466)$ usefully clarifies that 'heterotopias are not places as such but a relationship established between the non-discursive elements of the environment, the space of seeing or visual apparatus in Deleuze's terms, that comes together with the space of discourse that surrounds it and is folded into it'. The Castle, therefore, could be understood to be a heterotopia and K.'s failed quest to be the result of his inability to engage with it outside of the physical and literal. Beyond the space of seeing, what came increasingly to matter in glimpsing the world of two-year-olds was to access the space of sensing, feeling and 
emotion, what these evoked and how they transformed meanings as we interacted with objects and each other.

Exploring the concept of heterotopia, Foucault (2002b) pursues a line of flight which draws on Velasquez's painting, Las Meninas. He does this to illustrate the complex relationship between physical form, the places from which it is encountered, the people who encounter it, what is represented and what is unseen or unrepresented, examining the perspectives of the painter, the model, the canvas, its contents, the painting's viewer and the interplay of meanings within and outside the painting:

the painter is ... looking out at us .... And yet this ... line of reciprocal visibility embraces a ... complex network of uncertainties, exchanges and feints ... the observer and the observed take part in a ceaseless exchange ... The painter is observing a place which, from moment to moment, never ceases to change its content, its form, its face, its identity (Foucault 2002b, 5)

This is what Deleuze and Guattari (2004) mean when they talk about not tracing but experimenting with the real. Also of interest in the painting is the mirror; Foucault (2002b) highlights how it is

more or less completely central ... it ought therefore, to be governed by the same lines of perspective as the picture; we might ... expect the same studio, the same painter, the same canvas to be arranged within it .... In fact, it shows us nothing of what is represented in the picture itself ... What it is reflecting is that which all the figures within the painting are looking at so fixedly, or at least those who are looking straight ahead (Foucault 2002b, 8)

This complexity, for Foucault (2002b), as for Kafka (1999), Deleuze and Guattari (2004) and Gordon (2011), is at the very heart of the everyday but extraordinary challenge of seeking to understand the relationship between notions of what the world is, what we do or do not experience of it, what is said or is not said about it and how we experience it, and what we and others say and feel (and have said and felt) about the world and its 
meanings (and what we say and feel about what others say, feel, have said and have felt). In The Castle, K. does not take sufficient account of Foucault's insight (2002b, 33) that

everything would be manifest and immediately knowable if the hermeneutics of resemblance and the semiology of signatures coincided without the slightest parallax. But because the similitudes that form the graphics of the world are .... out of alignment with those that form its discourse, knowledge and the infinite labour it involves, we find here the space that is proper to them: it is their task to weave their way across this distance, pursuing an endless zigzag course from resemblance to what resembles it.

The misalignment requires complex sparking and connectivity, that $\mathrm{K}$. does not make, across the parallax of apparently unrelated ideas and activities. This is also what Deleuze and Guattari (2004) are referring to when they say that forms of representation are not images of the world but rather form rhizomes with it. This is significant for the project's concern to examine knowledge about, and practice with, two-year-olds. These are the very ideas with which we engaged as we thought about two-year-olds, how we work with them and the hegemonic discourses that make certainties appear so 'real' in policy documents. The notion of heterotopia is useful to us, therefore, in seeking to think about and experience the complex, multi-directional and contested understandings regarding two-year-olds and ways of working with them.

The interplay of power in space, discourse and time creates another feature of heterotopias: how they operate both as mechanisms of discipline on the one hand and of escape on the other. Kafta's Castle can be similarly understood. In terms of discipline and control, Foucault $(2002 \mathrm{~b}, 180)$ identifies 'crisis heterotopias...reserved for individuals who are in a state of crisis with respect to society and the human milieu in which they live'. Whilst these are disappearing, they are 'being replaced ...by ... heterotopias of deviation' for individuals whose behaviour is deviant with respect to the mean or required norm' (Foucault 2002b, 180). Exploring the parallax between two-yearolds, early childhood settings and their practices therefore also involves understanding the ways in which power could be seen to operate through early years' settings to compensate in families framed as 'deviant', where the experiences are perceived as impoverished, 
lacking, chaotic, unprofitable. Following Foucault (2002b, 184), power then operates through the heterotopic early childhood setting to create 'a different space .... as perfect, as meticulous, as well-arranged as ours is disorganised, badly arranged and muddled.'

Convention and regulation are also evident in the Castle, a place whose hold over the village is suggestive of Foucault's panopticon (2002a), with its ready and constant central observation and surveillance over all the radiating prison corridors and their clear view of the elevated panopticon. Both officials and servants, freed from the conventions and restrictions of the castle, drink at the inn and have affairs but these actions have consequences. We are warned of one family which has suffered both rejection by the village as in looks back towards the Castle and the withdrawal of the Castle's support because the daughter refused the advances of one of its officials. Nothing they do is deemed sufficient to compensate, moving them from a position of respect to one of ostracism, ill health and poverty. With this in mind, our concern was to avoid becoming easily seduced by the state's imperatives about what children should be and be provided with but we were attentive to the need for care of the self as part of resistance if practitioners were to be successful in negotiating the dominant discourses.

\section{Bouncing on the Springs of Early Childhood and Professional Development}

As well as exploring heterotopias' disciplinary mechanisms, we were interested in their freeing aspects:

it's Thursday afternoons on their parent's bed. It is on that bed where they discover the ocean, as they can swim between the covers, and the bed is also the sky, or they can bounce on the springs; it's the forest as they can hide there; or still, it's night as they can become ghosts between the sheets. (Johnson 2013, 798, translation of Foucault $(2010,24)$

Shah (2014: 714) highlights that 'heterotopias ...act as indicators of transformation, rupturing the discourses of normality .... they can also be transformative'.

Engaging with early childhood experiences as offering escape from dominant and pre-existing ways of learning, knowing and understanding is no easy matter, however. The project's heterotopic challenge was to disrupt the space between the places, practices 
and artefacts of early childhood and the ghosts of the different discourses associated with them in neoliberal policy documents in order to explore whether other ways of understanding children and childhood might come about. The next few professional development sessions (discussed Barron et al, 2017), pursued access to lines of flight through heterotopic physical and sensory exploration of every day experiences, such as box and den play. This involved the participants being encouraged by the professional development session leaders to experience such activities in the ways that children might, for example kissing, smelling, stroking, rubbing their faces against, licking, hitting and kicking the boxes. This was intended to eat and scape away at any notion of easy convergence between notions of what it means to be two years old, the practices that are commonly considered to be suitable and how these might be experienced both by children and adults. We sought to engage in a set of activities that 'disturbs and unsettles wherever it sheds its light' (Johnson 2013, 800), to bounce on the springs of the supposedly firm foundations of what matters in early childhood and to experience something of what this feels like. In so doing, we hoped to offer something more optimistic than the neoliberal determinism that is concerned whether particular types of early childhood experience are or are not conducive to early brain development, effective preparation for school and the production of economically viable state citizens. We also explored whether other kinds of experiences might open up other kinds of possibilities, other ways of being. There is little wonder, then, that we found exploring this parallax and the disciplining heterotopic early childhood setting and its practices to be deeply emotionally charged, to require attention to care of the self and perhaps we gave this too little attention.

\section{Exit through the Pound Shop}

The final session was in January 2016 and included almost all the practitioners and academics, including Ian and Lisa. It was led by the project director and reviewed what the project had meant for us and how it had affected our views about two-year-olds. The approach again sought to explore notions of parallax and refraction. The session was based on a film by the British street artist Banksy, entitled Exit through the Gift Shop, where a French shop-keeper decides to film the work of street artists around the world. He explains that this will become a documentary but never intends to edit it into a coherent narrative. Banksy (along with a number of other street artists) agrees to take part as long as he cannot be identified. Along the way, the shop-keeper/film maker begins to work as 
a street artist. Banksy persuades him to make the film but soon realises he does not have the skills and Banksy then turns this film and some footage of his own into a documentary about the shopkeeper's work on the film project. Hence we see the same heterotopic refraction of ideas and images that we had been working on throughout the project, and that Foucault (2002b) explores in discussing Las Meninas (see earlier), permeated this session too.

Its focus was a visit to a local discount shop and, as with many of the other professional development sessions, it occasioned a mixture of interest and anxiety. The participants walked to and from the shop together and, as not all had been at all of the professional development sessions, there was some re-familiarisation and sharing of experiences. Lisa was struck by the ease with which different groups formed and reformed and conversation flowed. For Lisa, this was reminiscent of the whole body of experiences but Ian, having been absent from a number of the professional development sessions, perhaps felt more like $\mathrm{K}$. in The Castle, experiencing anxiety about becoming acquainted with and accepted by the group. We talked about how we valued the opportunity it had given us to put ourselves in the shoes of a two-year-old, experiencing the vulnerability and curiosity of unfamiliar spaces. Once at the shop, we all had a British pound to buy something that represented our thinking about the project. Some made a quick purchase, others took longer; Ian and Lisa were amongst the last to choose. Whilst Lisa had experienced curiosity, Ian's overwhelming sense was of apprehension about what others might think about the choice made in terms of its adequacy in capturing the thinking about two-year-olds and professional development, especially having been absent from a good number of the development sessions. In the end, I (Ian), chose a set of Christmas lights and Lisa chose a candle. We were amongst several who made light-related choices.

Back at the university, we were invited to explain our choices. Many of us talked of feeling anxious about finding something interesting to say, especially as we listened to the contributions of others, awaiting our turn. Listening to the responses, I (Lisa) was reminded of the jam jar task and how our perspectives ranged from the tangible to the abstract, reflecting our thoughts, feelings and beliefs about two-year-olds. I was also struck by the way memories were strongly influenced by emotional responses. This has also led to further reflection on how long lasting change and development comes about through these emotional connections whether in working with practitioners or with two- 
year-olds. This begins to raise questions about whether this emotion is also the reason why the work can be so challenging and whether we pay sufficient attention to care of the self. In making my choice, a variety of themes crossed my mind. These included growing, changing, uniqueness and collaboration. This represented

the lighting of a spark in all the participants in different ways .... it was all around that light and spark, the candle melting and changing ... the layers of it made me think back to the start, about .. that twoyear-old agenda, but there's the different colours and the different shades and what does it mean to be a two-year-old in one place and .... in a different space so then I just got caught up in the different colours and different shades and thinking about working with different settings, different practitioners.

In explaining my choice of Christmas lights, I (Ian) talked about the particular kind of light given off but how they somehow look different once Christmas has gone, pointing to a parallax dislocation of the object from association, meaning and time, experimentation with but not tracing of the real. Thus, the spark of light in thinking about ways of working with young children is one image but others are possible as shadows can also appear and this, I felt, was what the project had been about. In The Castle, K. never seems to find a way of negotiating the gloom and the snow of winter but I talked of the way in which Christmas lights interrupt and disrupt this gloom and somehow provide an uplifting glow that is something more than but also part of the lights, what the Danish might call hygge. I reflected that

$$
\begin{aligned}
& \text { there is something about the lights through what is unsettling, } \\
& \text { uncomfortable, dislocated, that is somehow settling, pleasant and } \\
& \text { reassuring, that gives some sense of ..... I don't know - it's something } \\
& \text { about the glow from them ... how do you live with dislocation, how do } \\
& \text { you live with feeling uncomfortable, what do you need to hold on to ...... } \\
& \text { what gives you the glow to keep going. }
\end{aligned}
$$

I (Ian) recall coming home from the session, feeling some emotional turbulence, perhaps that of learning, and saying that I felt that I had been incoherent in talking about the choice that I had made, had failed to negotiate the project's quest. In watching the video extract, 
I get little sense of these feelings now. What does this mean for the 'truth' of what I felt at the time in relation to what appears on the video? Perhaps, as when K. falls asleep and almost misses Erlanger (who he sees as offering access to the Castle) leaving, 'this .... does not recount a failure at all. It is a deliberate red herring that makes us rethink what a “victory” in such a narrative might look like' (Ullyot 2010, 438). Thus, what it seems to reinforce is the sense of the parallax in seeking to understand what 'happened', the gearing of the cogs between 'the real' and the various ways we represent it. This juxtaposition of different meanings and feelings attached to the same experiences and events was exactly what the project was seeking to explore. Perhaps, however, it requires that appropriate attention is given to emotional well-being so that the daily task of engaging with the multiplicities and juxtapositions is tolerable. Maybe in doing this, there is some hope of escaping the desolation that $\mathrm{K}$. experiences in The Castle. This appeared as an important late new line of flight that may be significant to the future work of the project.

\section{Mapping the Real: Finding Ethical Ways of Working with Young Children?}

So what of the project's intention to challenge the sufficiency of dominant policy discourses about two-year-olds, and to seek to counteract the potentially bleak determinism of neuroscience's view of the first thirty-two months? We were mindful, like Azizmohammadi $(2012,2247)$ that 'life gives everybody an opportunity to make choices but never offers total freedom'. We do feel, however, that, through its experiences and ideas, the project allowed us to explore early childhood and its settings and practices as heterotopic, to encounter the parallax between and beyond the physical form of places, practices and artefacts. We sought to engage with seemingly familiar and self-evident beliefs and practices regarding work with two-year-olds in a heterotopic space 'that claws and gnaws at us' (Foucault 1984, 3) and where things were not as they first seemed. In doing this, we hoped to challenge some of the inequalities that haunt discourses about, and policy regarding, appropriate practice with young children.

This has led us through the distorting lens of the mirror, experiencing physically and through the senses as well as through what we see and hear. In so doing, the intention has been that this 'multiplicity never allows itself to be overcoded' (Deleuze and Guattari 2004, 9) but is made up of 'a continuous self-vibrating region of intensities, whose development avoids any orientation towards a culmination point or external end' (Deleuze and Guattari 2004, 24). This has involved engagement with a heterogeneity of theories 
and activities, sparking connections across axons and dendrites, in order to generate new synapses to help us think, act and feel afresh about work with young children and their families.

The challenge for practitioners, however, is that their success is measured in the very partial, but firmly coded, terms of children's progress in narrowly defined areas of learning and success in Ofsted inspections. With this in mind we need to consider whether it is ethical for researchers to open up complexity in this way but leave practitioners to resolve the tensions? Foucault $(2000 \mathrm{a}, 256)$ says that 'the ethico-political choice we have to make every day is to determine which is the main danger.' K.'s failed quest in The Castle seems to stem from his inability to identify the main dangers of both the village and the Castle. We felt that there was considerable danger from the government's pathologising of ways of being two-years-old. Our sense was that we needed, despite the difficulty for practitioners in their daily work with children, to support the tussle with the Castle as an ethical response to the dangers of dominant discourses. It is recognised that this is demanding as it means going beyond compliance with what neoliberalism requires in order to enter the uncertainties of what might be necessary and this is a risky business.

The majority of the academics sought to avoid the way that $\mathrm{K}$. left the villagers to face the workings of the Castle alone, agreeing with Steyaert $(2010,57)$ that 'resisting is not pleasant ... but it is clearly something that needs to be done repeatedly, daily'. K. never reaches the Castle because "he tries to fit the life of the Castle into his rationalist categories .... and ... he does not allow others to be themselves but uses them for his own purposes thus denying them any individuality which he wants for himself' (Azizmohammad, 2012, 2247). Though writing of The Trial (Kafka 2001), Shah (2014, 703) suggests that failure lies in the 'inability to exploit the possibilities of alternative ordering unlocked by heterotopic space.' Only latterly have I (W) come to see K. in myself and this has brought deeply uncomfortable recognition of how other project members engaged with resistance.

The Exit through the Pound Shop session and subsequent interviews suggest that the process had been a productive one and had enriched practice, rather than leaving practitioners unsure how to act, impotent in the face of neoliberal regimes of power. The project has sharpened attention to the significance of emotions in very young children's 
everyday experiences (and in how adults engage with the unfamiliar), the very direct daily contact that practitioners have with these emotions and the possible emotional consequences for them arising from the very nature of these encounters. In her diary account of this session, Lisa reflected on how she felt that emotion was at the heart of encouraging different ways of thinking about work with young children:

how do you make changes .... you've got to ... have that emotional connection with them - because it's only when they feel that emotion that they'll change ..... How do people change? Or how do you give them that permission, and that power to change?

This sounds rather like the whole complex business of learning. Paying more attention to the affective aspects of early childhood experiences requires that practitioners feel confident enough to take the risk of challenging dominant discourses. There was a growing sense from those involved throughout that this was worthwhile. I fear that I (Ian), rather like $\mathrm{K}$. in The Castle, never felt able to consider sufficiently the needs of others, focusing too much on my own priorities and sense of constraints. Indeed, it is important to note, as Steyaert $(2010,54)$ reminds us, that 'the care of the self implies trying to find freedom within power relations. As such we are always at the edge of our freedom, and our freedom is at the edge of our limits'. It is difficult work, requiring support for our own emotional well-being as we question very deeply held beliefs and feelings about practice with young children. These are tricky matters that offer the possibility of something 'all the more total for being fragmented' (Deleuze and Guattari 2004, 7) and ones with which both I (Ian) and the project seem likely to need to engage in the next phase as we strive to stay rhizomatic in questioning the dominance of the Castle, whilst also taking emotional care of the necessary underground connections.

\section{Acknowledgements}

I would like to thank the project lead, Rachel, for invaluable comments on drafts of this paper.

\section{Disclosure statement}

No potential conflict of interest. 


\section{Funding}

This research received no specific grant, other than an internal university one, from any funding agency in the public, commercial or not-for-profit sectors.

\section{References}

Andrew, Y. 2015. "Beyond Professionalism: Classed and Gendered Capital in Childcare Work." Contemporary Issues in Early Childhood 16 (4): 305-321, DOI:10.1177/1463949115616322

Azizmohammadi, F. 2012. "A Psychological Analysis on Franz Kafka's The Castle." Journal of Basic and Applied Scientific Research 2(3): 2243-2248

Barron I, L. Taylor, J. Nettleton and S. Amin (2017) Working with the cracks in the rigging in early childhood professional development. Contemporary Issues in Early Childhood. First published on line: 8 February 2017, DOI: 10.1177/1463949117692272

Bath, C. and R. Karlsson. 2016. "The Ignored Citizen: Young Children's Subjectivities in Swedish and English Early Childhood Education Settings." Childhood 23(4): 554565, DOI: 10.1177/0907568216631025

Blaise, M., C. Hamm \& J.M. Iorio. 2016. "Modest Witness(ing) and Lively Stories: Paying Attention to Matters of Concern in Early Childhood." Pedagogy, Culture \& Society, DOI: 10.1080/14681366.2016.1208265

Bourke, T. and J. Lidstone. 2015 "What is Plan B? Using Foucault's Archaeology to Enhance Policy Analysis." Discourse: Studies in the Cultural Politics of Education 36 (6): 833-853, DOI: 10.1080/01596306.2014.903611

Burman, E. 2016. "Knowing Foucault, Knowing You: Raced/Classed and Gendered Subjectivities in the Pedagogical State." Pedagogy, Culture and Society 24 (1): 1-25, DOI: $10.1080 / 14681366.2015 .1057215$

Deleuze, G, and F. Guattari. 2004. A Thousand Plateaus. Translated by Brian Massumi. London: Continuum

Department for Education. 2011. Supporting Families in the Foundation Years. London: Crown Copyright.

Department for Education. 2014. Statutory Framework for the Early Years Foundation Stage. London: Crown Copyright.

Ecclestone K. \& K. Brunila. 2015. "Governing emotionally vulnerable subjects and 'therapisation ' of social justice.” Pedagogy, Culture \& Society 23 (4): 485-506, DOI: 10.1080/14681366.2015.1015152. 
Elfer, P. 2012. "Emotion in Nursery Work: Work Discussion as a Model of Critical Professional Reflection." Early Years $32 \quad$ (2): 129-141, DOI:10.1080/09575146.2012.697877

Elfer, P. 2015. "Emotional Aspects of Nursery Policy and Practice - Progress and Prospect." European Early Childhood Education Research Journal 23 (4): 497-511. DOI: 10.1080/1350293X.2013.798464

Foucault, M. 1984. "Of Other Spaces: Utopias and Heterotopias". Translated by Jay Miskowiec. Architecture/Mouvement/ Continuité, October, 1984 (Des Espace Autres, March 1967).

Foucault, M. 2000a. Ethics: Essential Works, Volume 1. Translated by Robert Hurley and Others. London: Penguin.

Foucault, M. 2000b. Aesthetics: Essential Works, Volume 2. Translated by Robert Hurley and Others. London: Penguin.

Foucault, M. 2002a. Power: Essential Works, Volume 3. Translated by Robert Hurley and Others. London: Penguin.

Foucault, M. 2002b. The Order of Things: An Archeology of the Human Sciences. Translated by Tavistock Publications Limited, 1972. London: Routledge Classics.

Foucault, M. 2010. Les Corps Utopique, Les Hétérotopies. Clamercy: Éditions Lignes.

Gopnik, A, A. Meltzoff and P. Kuhl. 2001. How Babies Think: The Science of Childhood, London: Phoenix

Gordon, A. 2011. "Some Thoughts on Haunting and Futurity." Borderlands, 10 (2): 1-21, http://averygordon.net/files/GordonHauntingFuturity.pdf

Hackett, A. 2016 "Young Children as Wayfarers: Learning about Place by Moving Through It." Children and Society 30: 169-179, DOI: 10.1111/chso.12130.

Hetherington, K. 2011. "Foucault, the Museum and the Diagram." The Sociological Review 59 (3): 458-475, DOI: 10.1111/j.1467-954X.2011.02016.x.

Hochschild, A.R. 1983. The Managed Heart: Commercialization of Human Feeling. Berkeley: University of California Press.

Hohti, R. 2016. "Now — and Now — and Now: Time, Space and the Material Entanglements of the Classroom." Children and Society 30: 180-191, DOI: 10.1111/chso. 12135 .

Johnson, P. 2013. "The Geographies of Heterotopia." Geography Compass 7 (11): 790803, DOI: $10.1111 /$ gec3.12079

Jones, L. 2001. "Trying to Break Bad Habits in Practice by Engaging with Poststructuralist Theories." Early Years 21(1): 25-32. 
Kafka, F. 1999. The Castle. Translated by Willa and Edwin Muir. London: Vintage.

Kafka F. 2001. The Trial. Translated by Marco Pedulla. London: Vintage.

Lacan, J. 2001. Ecrits: A Selection. Translated by Alan Sheridan. London: Routledge

Lapadat, J.C. 2009. "Writing Our Way into Shared Understanding Collaborative Autobiographical Writing in the Qualitative Methods Class." Qualitative Inquiry 15 (6): 955-979, DOI: 10.1177/1077800409334185.

Lenz Taguchi, H. 2011. "Investigating Learning, Participation and Becoming in Early Childhood Practices with a Relational Materialist Approach." Global Studies of Childhood 1 (1): 36-50, DOI: 10.2304/gsch.2011.1.1.36.

Löfgren, H. 2016. “A Noisy Silence About Care: Swedish Preschool Teachers' Talk About Documentation." Early Years 36 (1): 4-16, DOI: 10.1080/09575146.2015.1062744.

Martinovic, M., N. Wiebe, S. Ratkovic, C. Willard-Holt, T. Spencer and M. CantaliniWilliams. 2012 "Doing Research was Inspiring: Building a Research Community with Teachers." Educational Action Research 20 (3): 385-406, DOI:

10.1080/09650792.2012.697402

Osgood, J. 2010. "Reconstructing Professionalism in ECEC: The Case for the 'Critically Reflective Emotional Professional." Early Years 30 (2): 119-133, DOI: $10.1080 / 09575146.2010 .490905$

Rautio, P. 2014. "Mingling and Imitating in Producing Spaces for Knowing and Being: Insights from a Finnish Study of Child-Matter Intra-action.” Childhood 21 (4): 461-474, DOI: $10.1177 / 0907568213496653$

Rhedding-Jones, J. 2008. "The OECD and the Notion of Expert in Early Childhood Education and Care: A Play." International Critical Childhood Policy Studies 1 (1): 2841, DOI: $10.1057 / 9781137346889.0011$

Ryan, S. and S. Grieshaber. 2005. "Shifting from Developmental to Postmodern Practices in Early Childhood Teacher Education." Journal of Teacher Education 56 (1): 34-45, DOI: $10.1177 / 0022487104272057$

Shah, R. 2014. "Urban Panopticism and Heterotopic Space in Kafka's Der Process and Orwell's Nineteen Eighty-Four." Criticism 56 (4): 701-723, DOI: 10.13110/criticism.56.4.0701.

Shonkoff, J. and D. Phillips, eds. 2000. From Neurons to Neighborhoods: The Science of Early Childhood Development. Washington: National Academy Press.

Steyaert, C. 2010. "Queering Space: Heterotopic Life in Derek Jarman's Garden.” Gender, Work and Organization 17 (1): 45-68, DOI: 10.1177/1350508411401946 
Ullyot, J. 2010. “Kafka's Grail Castle.” The German Quarterly 83 (4): 431-448, DOI: 10.1111/j.1756-1183.2010.00094.x

Wesselman, D. 2013. “The High Line, 'The Balloon', and Heterotopia.” Space and Culture 16 (1): 16-27, DOI: 10.1177/1206331212451669. 